\title{
BMJ Open Delineating the concept of self-management in chronic conditions: a concept analysis
}

\author{
Dominique Van de Velde, ${ }^{\oplus, 2}$ Freya De Zutter, ${ }^{1}$ Ton Satink, ${ }^{3}$ Ursula Costa, ${ }^{4}$ \\ Sara Janquart, ${ }^{1}$ Daniela Senn, ${ }^{5}$ Patricia De Vriendt ${ }^{\oplus 1,2,6}$
}

To cite: Van de Velde D, De Zutter F, Satink T, et al. Delineating the concept of self-management in chronic conditions: a concept analysis. BMJ Open 2019;9:e027775. doi:10.1136/ bmjopen-2018-027775

- Prepublication history and additional material for this paper are available online. To view these files, please visit the journal online (http://dx.doi. org/10.1136/bmjopen-2018027775).

DVDV and FDZ contributed equally.

Received 9 November 2018 Revised 13 May 2019 Accepted 3 June 2019

Check for updates

(C) Author(s) (or their employer(s)) 2019. Re-use permitted under CC BY-NC. No commercial re-use. See rights and permissions. Published by BMJ.

For numbered affiliations see end of article.

\section{Correspondence to}

Prof. Dr. Dominique Van de Velde;

dominique.vandevelde@ugent. be

\section{ABSTRACT}

Objectives Self-management is a concept frequently used within healthcare but lacks consensus. It is the aim of this study to clarify the concept.

Design Concept analysis according to Walker and Avant, comprises eight steps: select concept, determine purpose, identify uses, determine defining attributes, identify model case, identify additional cases, identify antecedents and consequences and define empirical referents. Sources used: PubMed, Scopus and Web of Science.

Results Ten attributes delineating the concept have been identified and organised into three groups. Group (a): person-oriented attributes: the person must (1) actively take part in the care process, (2) take responsibility for the care process and (3) have a positive way of coping with adversity. Group (b): person-environment-oriented attributes: (4) the person must be informed about the condition, disease and treatment and self-management, (5) should be individualised, which entails expressing needs, values and priorities, (6) requires openness to ensure a reciprocal partnership with healthcare providers and (7) demands openness to social support. Finally, Group (c): summarising attributes: self-management (8) is a lifetime task, (9) assumes personal skills and (10) encompasses the medical, role and emotional management.

Conclusions The findings of this study recognise the complexity of the concept, but also show the need for further investigation to make the concept more measurable. Clarity about the concept will enhance understanding and facilitate implementation in selfmanagement programmes for chronic conditions.

\section{INTRODUCTION}

To date, the discourse on defining health is shifting from the current static WHO definition health is a state of complete physical, mental and social well-being and not merely the absence of disease or infirmity ${ }^{11}$ towards a more dynamic definition, in which health is defined as 'the ability to adapt to one's environment.' 2 Researchers and scholars have elaborated further on this conceptual idea and propose incorporating the concept of self-management in the definition: health is 'the ability to adapt and self-manage in the face of social, physical, and emotional challenges'. ${ }^{3}$ The main

\section{Strengths and limitations of this study}

- With this study, we suggest that the concept of self-management should be researched in greater depth before it can be used as a key aspect of health.

The study enhances the understanding of the concept of self-management, offers opportunities for measuring it and provides a strong basis for developing self-management programmes.

- While a concept analysis explores current perspectives, a consequence is that the current findings could change within a few years depending on the new knowledge that emerges from new insights.

- A limitation of a concept analysis is the non-random sampling method, meaning that there might be a selection bias.

- This resulted in a contemporary image of self-management based on saturation of the data and not on a comprehensive overview of all relevant articles as could have been the case in, for instance, a systematic review.

argument for this transition is because of the demographic and epidemiological evolution characterised by an increase in non-communicable diseases within the context of multimorbidity. ${ }^{4-7}$ As a consequence, besides attempting to cure the disease, healthcare delivery shifts towards empowering patients to self-manage the consequences of their condition. ${ }^{3}$

In this regard, interventions for self-management are increasingly implemented in healthcare delivery for people with chronic conditions. Based on the results of a systematic review by Panagioti $e t a l,{ }^{8}$ it is shown that interventions directed towards self-management significantly improve health outcomes, resulting in a reduction in healthcare utilisation in association with decreases in health. ${ }^{8}$ As a consequence of growing evidence, it can be agreed that there are indeed arguments in favour of changing towards a more dynamic definition of health in which self-management is a key concept. 
However, there is no consensus on the meaning of self-management. The ambiguity of the concept is shown by the sheer number of randomised controlled trials of self-management interventions for chronic diseases. In these studies, self-management has been operationalised in different ways and types of interventions, ranging from education programmes to shared goal-setting programmes, tailored physical activity programmes or fitness programmes, behavioural skills training, activity-oriented programmes and comprehensive programmes combining different features. ${ }^{9-17}$ Each of these features reported in the studies may well enhance the ability for patients to undertake better management of their chronic illnesses. However, there is no rationale in terms of whether these programmes should meet certain criteria to be considered effective in fostering self-management behaviour. In addition, different definitions of the concept and different outcome measures have been used in these studies, such as self-efficacy, health-related quality of life, functional capacity, activity participation, performance of activities in daily living, illness cognition, work absenteeism, depression, self-confidence and fatigue. ${ }^{11-22}$ Only two studies report having measured self-management behaviours. ${ }^{23}{ }^{24}$ It is therefore difficult to compare the interventions and results.

This apparent ambiguity regarding the concept of self-management impedes the efforts of researchers and practitioners to implement and measure the concept in programmes and interventions. Jonkman et $a l^{25}$ and Pearce $e t a l^{26}$ declared that a lack of taxonomy and a further subdivision of the aspects of self-management hinders our general understanding of what it means and entails. In view of the numerous publications and the variety of descriptions of self-management, there is an urgent need for uniformity with regard to the concept. From this perspective, there is also a lack of evident value in incorporating self-management into any new health definition.

With this study, we hope to address this shortcoming and suggest that the concept of self-management should be researched in greater depth before it can be used as a key aspect of health. In addition, a clearer definition of the concept of self-management will also support the development of self-management intervention programmes for use in chronic conditions and multimorbidity, as well as the development of self-management measurements.

The main aim of this study is to explore the existing ambiguity concerning the concept 'self-management' by delineating the concept itself and defining an operational definition for use in healthcare. Clarity on the concept will enhance understanding and facilitate the implementation of self-management programmes for chronic conditions.

\section{METHODS}

The eight-step concept analysis of Walker and Avant ${ }^{27}$ was performed to investigate the concept, as follows: (a) select a concept, (b) determine the aims or purposes of analysis, (c) identify the use of the concept and select the literature, (d) determine the defining attributes, (e) identify a model case, (f) identify additional cases, (g) identify antecedents and consequences and $(\mathrm{h})$ define empirical referents. These eight steps are presented chronologically, but in reality, they were undertaken in an iterative manner.

\section{Step 1: select the concept}

This step derived from a joint international project (JIP) on 'health promotion and self-management' between partners from Ghent University (Belgium), HAN University of Applied Sciences (the Netherlands), the Metropolia University of Applied Science (Finland), the Health University of Applied Sciences (Austria), the School of Nursing Portuguese Red Cross Oliveira de Azeméis (Portugal), Artevelde University College Ghent (Belgium), University College Absalon (Denmark), FH Joanneum University of Applied Science (Austria), the National Sports Academy (Bulgaria), Brunel University London (UK), FH Campus Wien University of Applied Science (Austria), Zurich University of Applied Science (Switzerland) and the School of Health Technology Lisbon (Portugal). The JIP is a multidisciplinary project involving students, researchers and lecturers working in collaboration on research and educational projects in health promotion and self-management. The expert discussions within this JIP over the past 5 years revealed, as in the literature, the lack of clarity about the concept of self-management.

\section{Step 2: determine the aims and purposes of the analysis}

Discussions within the JIP highlighted the need for an in-depth analysis to reach consensus about the concept, to determine what is attributed to the concept, and consequently to create clarity by eliminating ambiguity.

\section{Step 3: identify all uses of the concept}

The possibilities and contexts in which self-management can be understood are very broad and include computer science, business, human resources, economics, education, psychology, sports, cultural work and healthcare. ${ }^{28}$ However, the scope of this study was solely self-management, as it is implemented and applied in healthcare and retrievable from the healthcare literature.

The search (January 2018-February 2018) started by entering the following keywords in PubMed, Scopus and Web of Science: 'self-management', 'chronic disease' and 'healthcare'. The search strings for the different databases are given in online supplementary file 1 . The first selection was made and articles with the term self-management in the title or in the keywords were withheld. After this selection, articles were included if the article (a) discussed the theoretical or conceptual foundations of self-management, (b) were healthcare related, (c) were written in English and (d) had the full-text available. Articles solely focussing on the application of self-management programmes and self-management interventions 
without a theoretical support were excluded. Two researchers (FDZ, SJ) independently selected the articles based on the above inclusion and exclusion criteria (March-April 2018).

The process of saturation was characterised by two main features: triangulation of (a) resources and (b) researchers. Regarding the resources, three different databases were used and the references in the selected articles were checked which led to additional articles that we also analysed. Articles including new knowledge were added to the data for further analysis; articles concerning previously reported information were withheld, but only to confirm the information provided. Regarding the triangulation of the researchers, after the first author and the last author, all other authors in this project were asked to critically read the gathered information and see whether possible published information was missing. When information was missing, they were asked to forward articles. This process was characterised by the iterative process of adding new knowledge and information until saturation was reached. Peer debriefing with the entire research group and a final consensus meeting led to an agreement of saturation (June 2018).

\section{Step 4: determine the defining attributes}

Attributes are considered an unequivocal feature of the concept. A systematic and purposeful approach was applied to discover the defining attributes, antecedents and consequences by: (a) reading the selected articles, (b) identifying the characteristics designated for self-management, (c) placing frequently occurring characteristics into a coding scheme, (d) grouping these characteristics and classifying them into categories, (e) discussing the categories and underlying characteristics with experts and (f) renaming the categories as attributes.

\section{Step 5: identify a model case}

A model case representing all attributes was identified by the second author based on real-life experiences of working with patients with a chronic condition, and was developed as a narrative to illustrate how self-management could be conceptualised. This case is supplemented with an overview of the attributes represented.

\section{Step 6: identify additional cases}

In addition, borderline and contrary cases were sought and corresponding narratives were written. These additional cases mitigate judgements about including and excluding certain attributes. These cases differ from the model case because they do not include all of the attributes and/or differ in one of them, such as length of time or intensity of occurrence. An overview is also given with those attributes that are represented and lacking. In describing a contrary case, an example of a specific case in the study by Bodenheimer et al was used to give a clear example of what does not reflect self-management. ${ }^{29}$

\section{Step 7: identify antecedents and consequences}

Antecedents are events or attributes that must arise prior to a concept's occurrence. For instance, if pain is the concept under investigation, an antecedent could be a fall. The consequences are those events or incidents that can arise as a result of the occurrence. For instance, regarding the concept pain, a consequence could be a fear of falling. The antecedents and consequences were discussed with all authors to reach a consensus. This phase was started at the same time as step 4 , but was an ongoing phase.

\section{Step 8: define empirical referents}

Ultimately, empirical referents were determined for each of the defined attributes to make the concept measurable in a more uniform way.

\section{RESULTS}

For clarity, the presentation of results in this paper is also organised according to the eight steps. However, the main result starts from step 4: defining the attributes. Steps 1-3 are clustered into one paragraph and show the literature on which the concept analysis was based.

\section{Steps 1-3}

Screening the titles and keywords of the articles initially yielded 128 articles, of which 118 did not meet the inclusion and exclusion criteria. The remaining 10 articles were used as a starting point; based on the triangulation of resources, 23 articles were added to the list while 2 articles were added based on the triangulation of researchers (figure 1). This finally resulted in 35 articles (table 1 ). These articles were used to describe the attributes of self-management and were subdivided into three groups: articles about self-management in general $(n=9)$, articles in which self-management was linked to chronic conditions and diseases $(n=13)$ and articles in which self-management was diagnosis-specific $(n=13)$. The analysis of these 35 articles was grounded on different points of views (ie, stakeholder, therapist and patient) and based on research from different countries. The average population consisted of white, middle-class patients from the following countries: the USA $(n=14)$, Canada $(n=9)$, the UK $(n=6)$, Australia $(n=3)$, the Netherlands $(n=2)$, Sweden $(n=2)$, Iran $(n=1)$ and South Africa $(n=1)$.

\section{Step 4: attributes}

These attributes are the result of an in-depth analysis of the different articles. Each of the attributes are the result from analysing the content of the articles in codes and categories. Online supplementary file 2 gives an overview of the categories and the accompanying codes with the referenced article to show the rigour of the study. To improve the readability of the findings, the different attributes are organised in: (1) person-oriented attributes, (2) person-environment-oriented attributes and (3) summarising attributes. It needs, however, some 


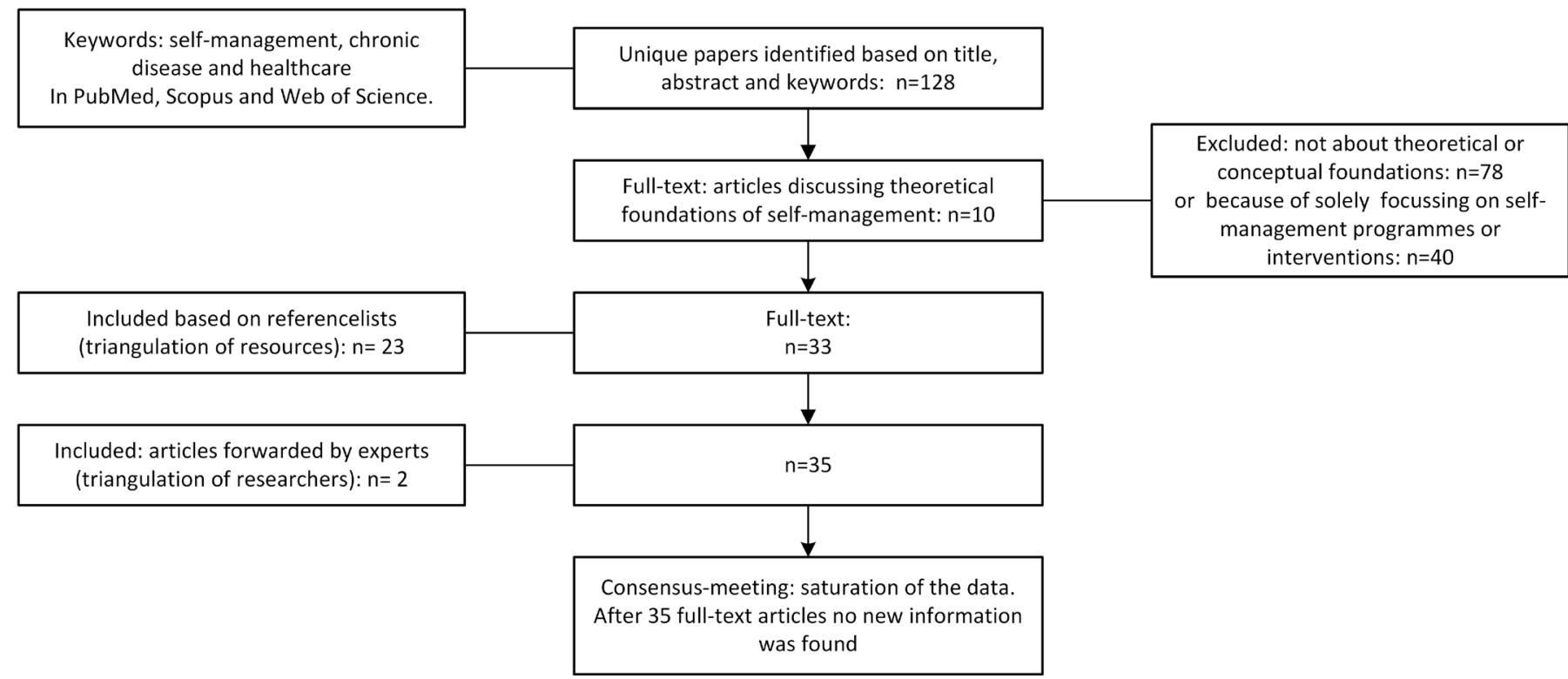

Figure 1 Flow chart demonstrating the search strategy, triangulation and saturation process.

attention, as none of the attributes can be considered as stand-alone items and should be seen in conjunction with all other attributes. Table 2 shows a total of 10 attributes, which are further described separately.

\section{Person-oriented attributes}

Attribute 1: the person must actively take part in the care process

The main aspect here is that the patient is also expected to actively participate in the care process. ${ }^{30-32}$ In undertaking self-management, a patient cannot be passive. ${ }^{33} 34$ Self-management implies increased active patient engagement, wherein an active attitude regarding treatment planning and management of health issues is required. $.^{83} 35-38$ Ellis $e t a \hat{l}^{37}$ consider that 'being proactive' can be viewed as a characteristic of a social citizen, which goes a step further than 'being active', given the preventive nature of the prefix 'pro'. In addition, Packer ${ }^{32}$ explained that self-management is gained through conscious and planned engagement.

\section{Attribute 2: the person must take responsibility for the care process}

This attribute is closely linked to the preceding attribute, but there is a subtle difference. The key message of this attribute is that the patient has to be active, and must take responsibility for the care, regardless whether or not there is a social network of family, friends and other proxies on whom the patient can rely or can consult with trust. Lorig and Holman ${ }^{34}$ state that the patient is the only actor within the care process who can be responsible for day-to-day care. This personal responsibility of the patient is also acknowledged by Edworthy ${ }^{39}$ and Ellis $e a$ al $^{37}$ The latter researchers termed an individual's responsibility 'self-governance' and identified it as a characteristic of a 'remoralised' social citizen. In contrast, Bodenheimer et $a l^{33}$ delineate self-management a shared responsibility for making and carrying out health-related decisions. The latter shows the importance of the ability to collaborate and rely on others and is described in attributes 6 and 7 .

Attribute 3: the person has a positive way of coping with adversity Persons with a chronic condition have to deal with emotions such as anger and frustration. Different authors argue that self-management is difficult when a person does not accept the disease and does not have a feeling of control about the situation. Omisakin and Ncama ${ }^{28}$ describe 'self-help' as a way of coping with adversity, which refers to the ability to care for oneself to assure one's own health and well-being and is endorsed by Ellis $e t a l^{37}$ This proposition implies the individual responsibility of the person mentioned in relation to attribute 3 mentioned above. When a person has a positive way of coping with adversity, others are more easily induced to acknowledge the responsibility of the person and expect the person to act as autonomously as possible. ${ }^{37}$ This means that patients are acknowledged in making decisions about their own health issues, with or without help from proxies and important others, and possibly with professional input. However, the patient is first and foremost self-reliant in making decisions, or should at least be informed about the different possibilities. ${ }^{28}$ In contemporary discourse, being autonomous is a moral obligation on the part of the patient towards society because autonomous patients do not use the welfare state inappropriately. ${ }^{37}$

\section{Person-environment-oriented attributes}

Attribute 4: the person must be informed about the condition, disease and treatment

A person cannot take responsibility and take action, unless he is correctly informed about his health condition and the possible consequences. Packer ${ }^{40}$ highlights that knowledge needs to be underpinned by information, confidence and support to achieve self-management. Indeed, several authors are convinced of the importance 
Table 1 Selected articles used for defining the attributes

No. Year Author(s) Title

Unique papers identified based on title and keywords

11991 Clark, Becker, Janz, Lorig, Rawkowski, and Self-management of chronic disease by older adults: a review Anderson

22002 Barlow, Wright, Sheasby, Turner, and Self-management approaches for people with chronic conditions: Hainsworth a review

32003 Lorig and Holman

Self-management education: history, definition, outcomes and mechanisms

\begin{tabular}{lll}
4 & 2011 & Packer \\
\hline 5 & 2011 & Richard, and Shea \\
6 & 2012 & $\begin{array}{l}\text { Schulman-Green, Jaser, Martin, Alonzo, } \\
\text { Grey, McCorkle, Redeker, Reynolds, and } \\
\text { Whittemore }\end{array}$ \\
7 & 2015 & $\begin{array}{l}\text { Boger, Ellis, Latter, Foster, Kennedy, Jones, } \\
\text { Fenerty, and Demain }\end{array}$
\end{tabular}

An occupation-focused approach to self-management

Delineation of self-care and associated concepts

Processes of self-management in chronic illness

\begin{tabular}{ccl}
\hline 8 & 2015 & Miller, Lasiter, Ellis, and Buelow \\
9 & 2016 & $\begin{array}{l}\text { Audulv, Packer, Hutchinson, Roger, and } \\
\text { Kephart }\end{array}$ \\
10 & 2017 & $\begin{array}{l}\text { Ellis, Boger, Latter, Kennedy, Jones, Foster, } \\
\text { and Demain }\end{array}$ \\
\hline
\end{tabular}

Self-management and self-management support outcomes: a systematic review and mixed research synthesis of stakeholders views

Chronic disease self-management a hybrid concept analysis

Concept analysis - coping, adapting or self-managing: what's the difference? A concept review based on the neurological literature

Conceptualisation of the 'good' self-manager: a qualitative investigation of stakeholder views on the self-management of long-term health conditions

Included articles based on triangulation of resources

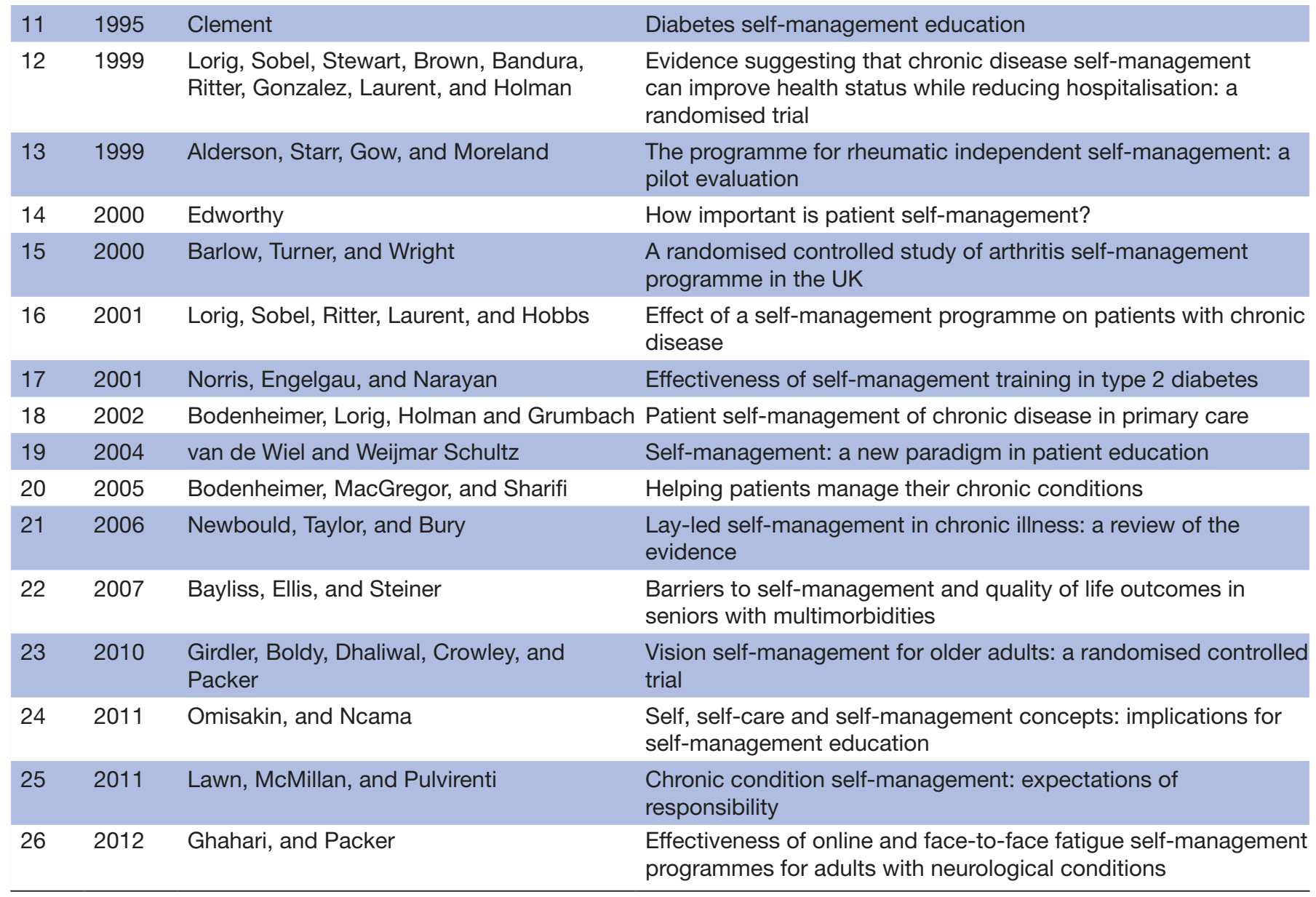


Table 1 Continued

\begin{tabular}{|c|c|c|c|}
\hline No. & Year & Author(s) & Title \\
\hline 27 & 2013 & Packer & $\begin{array}{l}\text { Self-management interventions: using occupational lens to } \\
\text { rethink and refocus }\end{array}$ \\
\hline 29 & 2014 & $\begin{array}{l}\text { Panagioti, Richardson, Small, Murray, } \\
\text { Rogers, Kennedy, Newman, \& Bower }\end{array}$ & $\begin{array}{l}\text { Self-management support interventions to reduce healthcare } \\
\text { utilisation without compromising outcomes: a systematic review } \\
\text { and meta-analysis }\end{array}$ \\
\hline 30 & 2014 & $\begin{array}{l}\text { Richardson, Loyola-Sanchez, Sinclair, } \\
\text { Harris, Letts, Macintyre, \& Ginis }\end{array}$ & $\begin{array}{l}\text { Self-management interventions for chronic disease: a systematic } \\
\text { scoping review }\end{array}$ \\
\hline 31 & 2014 & Thille, Ward, and Russell & $\begin{array}{l}\text { Self-management support in primary care: enactments, } \\
\text { disruptions and conversational consequences }\end{array}$ \\
\hline 32 & 2016 & $\begin{array}{l}\text { Raymond, Levasseur, Chouinard, Mathieu, } \\
\text { and Gagnon }\end{array}$ & $\begin{array}{l}\text { Stanford chronic disease self-management programme in } \\
\text { myotonic dystrophy: new opportunities for occupational } \\
\text { therapists }\end{array}$ \\
\hline \multicolumn{4}{|c|}{ Included articles based on triangulation of researchers. } \\
\hline 34 & 1997 & Clark, Janz and Dodge. & Self-management \\
\hline 35 & 1998 & Dunbar, Jacobson, and Deaton & Heart failure: strategies to enhance patient self-management \\
\hline
\end{tabular}

The order of the articles in the table is first based on the different phases of the search strategy and second by date.

of the attribute 'knowledge' to execute good self-management. $^{31} 32373941-44$ This specific attribute includes obtaining and developing knowledge about the condition, disease and treatment, specifically to be informed as a patient. ${ }^{33} 39414245-49$ It also includes understanding of one's own life circumstances. ${ }^{41}$ Knowledge can be attained by gaining access to resources, and community and support services. ${ }^{84} 4244475051$

\section{Attribute 5: self-management is individually defined and entails expressing needs, values and priorities}

Individual differences between persons, on the level of disease, environment and personal features make that self-management cannot be undertaken by default. Self-management is ideally based on patients' perceived problems and their personal perceptions of their condition in the context in which they live. ${ }^{34} 52$ Therefore, patients should express their needs, values and priorities. ${ }^{47}$ Self-management will take shape depending on the individual's abilities. $^{45} 465354$ It is an individualised and personal concern and is patient-driven..$^{30} 323337414248495152$ Without the individual engagement of the patient, self-management cannot be pursued, which implies the patient's central role. ${ }^{47}$ This individual engagement aims to promote health in activities. ${ }^{55}$ Furthermore, when a patient is a self-managing individual, intrinsic motivation is needed. ${ }^{415456}$

\section{Attribute 6: self-management entails openness to ensure a reciprocal partnership with healthcare providers}

In attributes 1 and 2, it is stated that the person needs to be active and take responsibility. This shift demands a substantial effort from the person himself, but the analysis shows that there is the need to be openness to ensure a reciprocal relationship with the professionals as well. Bodenheimer et $a l^{29}$ state that there has been a shift from traditional care to collaborative care. Traditional care refers to professionals viewed as experts who tell patients what to do; in this case, the patients are passive agents. In collaborative care, such as expected in self-management there is a shared expertise. In the partnership between patients and healthcare providers, the professionals are experts about the disease and the patients are experts about their lives. ${ }^{29}$ An advantage of this way of thinking is that the person is open to receiving feedback from the healthcare provider, making it possible to continue the care process. ${ }^{57}$ When patients are self-managing, it implies that they are in favour of collaboration and guidance of physicians and other healthcare providers. ${ }^{33} 41-4345475256$ This means that a patient-provider partnership has to be built, in which the patient and the provider occupy equal positions and co-operatively work together. ${ }^{82-34} 3951$ This also means that the patient needs to know when to report changes to healthcare providers. A variety of communication strategies, for example, being assertive, are required to allow appropriate interaction with the healthcare provider. ${ }^{41} 4658$ Positive reinforcement in response to patient care questions is essential. ${ }^{39}$

Attribute 7: self-management entails openness to social support

Next to the open communication with healthcare providers, a supportive environment is equally important, 


\section{Table 2 Overview of attributes}

Person-oriented attributes

$\begin{array}{cl}\text { Attribute 1 } & \text { The person must actively take part in } \\ \text { the care process. } & \text { The person must take responsibility for } \\ \text { Attribute 2 } & \text { the care process. } \\ \text { Attribute 3 } & \text { The person must have a positive way } \\ \text { of coping with adversity. }\end{array}$

despite the requirement for self-managing patients to act autonomously and be responsible for their own care process. Such an environment is enabled through family support and relationships with peers and significant others. ${ }^{41} 424556$ These significant others refer to the entire self-management support system, which can consist of the patient's family, friends, volunteer groups. ${ }^{30}$ Miller $e t a \check{l}^{1}$ describe this as the social community environment. To strengthen the necessary relationships, the patient must communicate with family and with the environment in general. ${ }^{304651}$ Of note, Ellis $e t a \ell^{37}$ find it regretful that the origins of self-management lie in individualistic behavioural change approaches. In these models, the importance of social support is disregarded. They wish to emphasise the importance of combining individual responsibility and social support, the significance of which is also recognised by other authors. ${ }^{415759}$ Together with self-reliance, family and community support is necessary to fulfil a self-managing attitude. ${ }^{28}$

\section{Summarising attributes}

Attribute 8: self-management is a lifetime task

Since self-management is closely linked to chronic conditions, it is not a task that has an end point. Self-management is a lifetime task. ${ }^{33}{ }^{34}$ Ghahari and Packer ${ }^{61}$ elaborated on this and argued specifically that the management of symptoms, the emotional consequences and the impact of chronic conditions are everyday tasks for patients throughout their entire life.

\section{Attribute 9: self-management assumes personal skills}

To be able to fulfil this lifetime task, five skills recur in multiple articles when it comes to self-management, regardless of the type of condition. These skills are related to the other described attributes and summarise in a certain way the above-described person-oriented and person-environment-oriented attributes.

\section{Attribute 9.1: problem-solving}

The problem-solving ability of an individual is often discussed when self-management skills are explored. ${ }^{28} 2932344041$ This consists of problem definition, the generation of possible solutions, solution implementation and the evaluation of results. This skill does not entail dictating certain solutions for a specific problem, but rather the learning of skills to deploy solutions. Following Lorig and Holman, ${ }^{34}$ the concept of self-management is problem-based, or more specifically, based on patient-perceived problems.

\section{Attribute 9.2: decision-making}

Decision-making is the second recognised skill of self-management. ${ }^{3441}$ This skill is related to the 'informed patient' attribute, which is needed to make informed choices. ${ }^{37}{ }^{57}$ This skill can also be linked to the patient and healthcare provider partnership as self-management entails collaborative decision-making. ${ }^{33} 47$

\section{Attribute 9.3: using resources}

Having access to the right resources is also related to the 'informed patient' attribute. Using resources concerns learning how to find and use the right resources. ${ }^{47}$ Such resources could include websites, libraries, community agencies and so on. ${ }^{52}$

Attribute 9.4: forming a patient-healthcare provider partnership

This aspect of self-management has already been considered as a separate attribute. Several authors have described the importance of this partnership as an independent attribute of self-management. Notwithstanding, a few authors consider this partnership to be among the self-management skills. ${ }^{3462}$

Attribute 9.5: goal-setting, taking action and evaluating the attainment of goals

The fifth self-management skill is action planning, which is based on making a short-term action plan and implementing it. The need to recognise 'taking action' as a self-management skill is supported by more than one researcher. ${ }^{34} 40415152$ Action planning is also related to goal-setting because individuals need to establish goals before implementing them. ${ }^{4146485257}$ Eventually, the 
person should be able to evaluate whether the goals are met. Evaluation comprises core skills in personally evaluating personal needs, rather than an evaluation performed by healthcare providers. ${ }^{51}$

\section{Attribute 10: self-management encompasses medical, role and emotional domains}

This attribute is somehow distinct from the others because it merges the above-described attributes in three different domains in which self-management is relevant. This final attribute has to be considered as a comprehensive overview and shows the different layers of self-management. There is a need to focus on managing medical aspects (such as the ability to take medication on time), the reallife context (eg, going to the sports club) and how to deal with emotions (eg, frustration and feelings of loss). Generally, three domains are described: medical management, role management and emotional management. ${ }^{62}$ Many researchers ${ }^{29} 345059$ refer to these three domains, constructed by Corbin and Strauss. Audulv ${ }^{30}$ also refers to this subdivision of work, but mentions commonly used synonyms, such as illness-related work, biographical work and everyday work. Illness-related work reflects the management of symptoms or crisis prevention, which is often termed illness management. In addition, he equates managing work or household tasks with everyday life tasks or role management. Finally, he uses the term biographical work to reflect managing emotions or identity.

\section{Attribute 10.1: medical management}

The first domain, medical management is often disease-specific and includes both very complex and technical tasks (eg, dialysis at home), as well as quite simple tasks (eg, taking medicine). ${ }^{30}$ Certain researchers have stipulated that lifestyle changes must be undertaken to perform medical management. ${ }^{28}{ }^{41}$ In this regard, they suggest reducing lifestyle risk factors and promoting health (prevention and early intervention), for instance, through maintaining a therapeutic exercise regimen, adhering to a diet, using an inhaler, taking medicine and smoking cessation. ${ }^{3474860}$ Organising, planning and remaining compliant with a medication administration schedule are also part of medical management. ${ }^{32} 4163$ Also, self-monitoring and symptom management are required in medical management. ${ }^{29} 31325556$

Richard and Shea ${ }^{56}$ describe self-monitoring as the 'monitoring of specific physiologic parameters or symptoms of a health condition'. Certain researchers explicitly highlight the importance of monitoring changes in the health condition. ${ }^{28} 454849555863$ The concept analysis of self-monitoring written by Wilde and Garvin ${ }^{64}$ shows that two components give rise to seeking contact with health professionals or for patients to take action themselves. First, the individual needs to be aware of bodily symptoms, sensations, daily activities and cognitive processes. Second, self-monitoring implies taking measurements and reading and recording variables. This includes, for instance, using glucometers for diabetes, but also checklists and diaries. Some authors refer to self-monitoring as recording subjective and objective measurements. Also, recorded symptoms may be compared with measurements. ${ }^{64}$ Edworthy ${ }^{39}$ emphasises the importance of monitoring the level and the intensity of symptoms, for example, pain, in combination with collecting objective data, for example, blood pressure, while Clark et $a l^{42}$ underscore the usefulness of physical indicators. Lawn et at ${ }^{47}$ expand this list and-in addition to physical functioning-also consider the impact of emotional, occupational and social functioning. The major focus is on measurement, which is not the case with symptom management. ${ }^{64}$ While Wilde and Garvin $^{64}$ treat self-monitoring and symptom management as equal terms, Barlow et $a t^{11}$ consider self-monitoring to be an element of symptom management.

Symptom management can be viewed as 'subjective experiences reflecting changes in biopsychosocial functioning, sensations or cognition of an individual ${ }^{65}$ In contrast to self-monitoring, symptom management is independent of measurements. Another difference is that symptom management can be managed by the healthcare providers ${ }^{56}$ aiming to control the disease by recognising and responding to symptoms ${ }^{83047565961}$ and preventing further illness or accidents. $^{843}$

\section{Attribute 10.2: role management}

When self-managing patients assume the tasks of role management, they are deemed to maintain, change or create new meaningful behaviours or life roles with the purpose of managing the disease and its associated effects. This kind of management also includes reviewing the roles of an individual and afterwards accomplishing the essential adaptations or changes. ${ }^{29} 333439404347515961$ The fact that role management indicates behavioural changes is confirmed by the individualistic behavioural approaches on which self-management is based. ${ }^{37}$ Role management also involves coordination and planning if the accomplishment of everyday activities is no longer self-evident because of pain, fatigue and reduced mobility caused by chronic conditions, ${ }^{30}$ and requires attention to maintain meaningful participation and occupational engagement in self-management. ${ }^{32}$

\section{Attribute 10.3: emotional management}

Emotional management represents the ability to deal with emotions ${ }^{30}$ such as uncertainty, anger, depression, stress, etc. ${ }^{8041} 434749606166$ Emotional management encompasses the predominantly inner process of reviewing one's life goals and identities. The manner in which individuals with chronic conditions manage their emotions can influence the ways in which they perform their role and medical management. ${ }^{30}$

\section{Step 5: model case}

A model case is a fictive case in which the 10 attributes are apparent and consequently an example of a good self-manager. An example of David is given in box 1 .

\section{Step 6: additional cases}

\section{Borderline case}

A borderline case is also a fictive case, but a case in which attributes are lacking. An example of a borderline case is given in box 2 . 


\section{Box 1 Example of a model case}

David was 34 years of age and had been suffering from a specific heart disease for 4 years. Therefore, he had to quit his professional sports career. After an intensive follow-up during hospitalisation, including openheart surgery, David was allowed to return home. He had difficulties finding his way in a completely different lifestyle. He had always been very involved in sports, but after his operation he needed to slow down. Being diagnosed with a heart disease caused him anxiety, but continuing his sport could lead to heart failure and eventually death. As a result of the good information offered during the hospital stay, for example, an explaining of the general issues of his heart problems and healthy lifestyle, and the conversation about David's goals for the next months, he had been able to build an excellent and confident relationship.

He was very compliant with his medication schedule and had always had a healthy lifestyle. When he was discharged from hospital, he signed up for a patient education programme on heart diseases. The specialist as well as other healthcare providers worked in partnership with David, meaning that they involved him in (personalised) goal setting and action planning, as well as having a personalised evaluation with David. In the programme that was offered to David, information about the medical issues and ways to manage these, as well as social issues (role management) and emotional issues were discussed. As he had survived open-heart surgery, his faith in science and medicine was strengthened. His family, particularly his wife, were very supportive from when he was diagnosed. In his sports club he had made many friends who continued to support him, even when he reduced his sports activities. This very independent young man was used to solving problems when they occurred, making informed decisions and so on. For the last 4 years, he had been struggling with his inability to cope with his feelings of ineffectiveness. He was no longer allowed to play sports as much as he had 4 years previously. On the recommendation of his best friend, he decided to become a board member of his own sports club. In making that decision, he found joy again. He reviewed his life roles and found a new, meaningful role, namely being a board member. Thus, it was easier to cope with the feelings of incapacity and these were exchanged for feelings of joy and pride.

In the case of Thomas some attributes of self-management cannot be found: (a) a good relationship between the patient and healthcare provider is lacking; (b) despite knowing which agencies can provide him with assistance (ie, Thomas is informed), the attribute 'using resources'

\section{Box 2 Example of a borderline case}

Thomas was 47 years of age and had been diagnosed with chronic obstructive pulmonary disease 5 years ago. As soon as the diagnosis was made, he resolved to live a healthier lifestyle. He quit smoking and became interested in healthy cooking. His old mobile phone was exchanged for a smartphone, on which he installed many health and fitness software applications. His highly supportive friends and family knew Thomas to be a person who was eager to learn, very aware of his condition and had an autonomous personality. He was highly alert to symptoms that might indicate a complication in his chronic disease. However, the fact that he was self-confident also had some disadvantages. It took him a long time to consult his physician. Thomas did not have a good relationship with his personal doctor. His brother reported that Thomas had a negative attitude towards caregivers since their father's death.

\section{Box 3 Example of a contrary case}

Clara was 68 years of age and had been referred for treatment due to rheumatism in both hands. This patient refused to believe in the advantages of treatment, so started her treatment with some resistance. She had little insight into her condition and had no intrinsic motivation to improve. The doctor referred this patient to an occupational therapist to learn some joint-saving techniques. The treating therapist showed her which movements should be avoided and which alternatives could be offered. In the presence of the therapist, the patient-sometimes reluctantly-performed joint-saving techniques. Once Clara was home again, without the therapist's supervision, the joint-saving techniques were not applied, her medication was not taken and the pain and feelings of impotence increased. During her first therapy session, she told her occupational therapist, 'it came naturally, and it will leave the same way'. Furthermore, she continued to isolate herself from the outside world.

is missing; (c) there is too much focus on medical management, with no attention to role or emotional management. In this case, there is too great a focus on Thomas having a striking self-efficacy mechanism and being highly self-appointed, which is good for achieving certain aspects of self-management, but shifts other attributes to the background.

\section{Contrary case}

A contrary is a clear example of 'not the concept'. An example of a contrary case is given in box 3 .

The contradictions in the attributes can be observed in this case: Clara does not make efforts to take responsibility, she is knowledgeable only to a restricted extent, she is not actively involved in the care process, she does not act autonomously because she is dependent on the therapist, there is an imbalance in the relationship between therapist and patient, she is isolated from the outside world, no specific skills can be recognised and she does not experience managing her conditions as a lifetime task. As soon as she was discharged from hospital and thus institutional treatment, she stopped her care process.

The above-described cases show the complexity of self-management and the possibility to compare a good self-manager with a weak self-manager. When relating this to healthcare practice, these cases can be used as examples to check whether programmes or interventions cover all attributes, and what should be focused on when not all attributes are covered.

\section{Step 7: antecedents and consequences}

\section{Antecedents}

As described above, antecedents are events or attributes that must arise prior to the occurrence of self-management. After thorough discussion within the research group, we decided to classify self-efficacy and health literacy as the two main antecedents.

Self-efficacy is an antecedent because it is considered by different authors as 'one of the possible mechanisms by which self-management can be achieved'. ${ }^{34} 5156$ In 
addition, self-efficacy reflects the development of confidence to manage the aspects of the three domains of self-management, ${ }^{32} 3741$ to deal with chronic conditions and their consequences ${ }^{29} 3267$ and having the confidence that a specific behaviour can be accomplished. ${ }^{33} 3944$

A second important antecedent is health literacy; Mackey $e t a b^{68}$ implies that there is an association between health literacy and self-management skills. Kitt et al follow this premise and argue that a low health literacy implies poorer self-management behaviours and health literacy is therefore considered to be an antecedent of self-management. ${ }^{38}$

Furthermore, perceived health status, ${ }^{56}$ social support, health beliefs, motivation and coping are also referred to as antecedents. ${ }^{51}$

\section{Consequences}

The consequences are those events or incidents that arise after self-management. Having a self-managing attitude towards one's care process results in multiple consequences, including improved health outcomes, reduced mortality, improved functional ability, improved quality of life, reduced healthcare costs, improved personal experience, improved social participation, improved functional outcomes, improvements in health behaviours, improved self-efficacy, treatment adherence and reduced healthcare resource utilisation. ${ }^{30} 43505156$ Self-efficacy is thus also defined as a consequence, as well as being described as an antecedent in the above section. With this in mind, specific self-management techniques are taught to increase self-efficacy. ${ }^{39}$

However, the multiplicity of consequences deserves further explanation. First, the consequence improved health outcomes ${ }^{56}$ relates to improved "perceived health (psychosocial well-being, perceived stress and optimal health) ${ }^{50}$ and 'improved health status'. ${ }^{43}$ The consequence 'improved health outcomes' is also similar to the consequence 'disease status/severity (symptom frequency and severity, number of exacerbations and physiologic parameters) ${ }^{51}$ This consequence seems to be a diagnosis-specific consequence of self-management and is therefore also related to the consequence 'disease-related outcomes'. ${ }^{50}$ In addition, Warsi et a ${ }^{69}$ support the assumption that improved healthcare outcomes are disease-related. These disease-related outcomes include disease progression, control of pain, fatigue symptoms, cognitive symptoms and depression. ${ }^{50}$ Moreover, social participation (including activity level, keeping up social relationships, participation), personal experience (acceptance, positive self-image, control over negative feelings), functional outcomes (physical, emotional and social functioning) and quality of life are also described as consequences. ${ }^{50}$

\section{Step 8: empirical referents}

Empirical referents are measurable ways of demonstrating the possible application of self-management by checking whether the attributes can be measured. Unfortunately, none of the articles in the analysis specifically named the empirical referents for the entire concept of self-management. Therefore, each of the attributes was checked to establish whether there are tools to measure the attributes separately. The analysis showed that there is a plethora of tools that have been developed to measure these attributes. An overview of the measurement tool and examples of possible questions is given in table 3 .

\section{Schematic representation of the results: a self-management model}

A model was created to outline the attributes and show their interrelationships (figure 2).

\section{DISCUSSION AND CONCLUSION}

Self-management is a concept that is frequently used in healthcare. Unfortunately, there is considerable ambiguity regarding the concept. This concept analysis is an attempt to enhance agreement. It has resulted in 10 attributes delineating the concept organised into three groups: (a) person-oriented attributes, (b) person-environment-oriented attributes and (c) summarising attributes. Group (a): person-oriented attributes: the person must (1) actively take part in the care process (2) take responsibility for the care process; (3) have a positive way of coping with adversity. Group (b): person-environment-oriented attributes: (4) the person must be informed about the condition, disease and treatment and self-management (5) should be individualised and entails expressing needs, values and priorities, (6) requires openness to ensure a reciprocal partnership with healthcare providers and (7) demands openness to social support. Finally, group (c): summarising attributes: self-management (8) is a lifetime task, (9) assumes personal skills and (10) encompasses medical, role and emotional management.

As a final conclusion, a new definition has been proposed:

Self-management is the intrinsically controlled ability of an active, responsible, informed and autonomous individual to live with the medical, role and emotional consequences of his chronic condition(s) in partnership with his social network and the healthcare provider(s).

This definition and the 10 attributes we found might be an answer for the lack of taxonomy and subdivision of characteristics of self-management as recently stated by Jonkman $e t a l^{25}$ and Pearce $e t a l .{ }^{26}$ From this perspective, the results of this study offer opportunities to provide a basis to create coherent and comparable self-management programmes and could enhance the quality of healthcare delivery in dealing with chronic health conditions and multi-morbidity.

Relating these new insights to the broader literature on self-management shows that the existing evidence is still primarily on medical management, rather than on 
Table 3 Examples of measurement tools and examples of possible questions

\begin{tabular}{|c|c|c|}
\hline Attribute & Example of a measurement tool & the attribute \\
\hline \multicolumn{3}{|c|}{ Person-oriented attributes } \\
\hline 1 & Self-Advocacy Scale (SAS) ${ }^{78}$ & I frequently make suggestions about my healthcare needs. \\
\hline 2 & $\mathrm{SAS}^{78}$ & $\begin{array}{l}\text { Sometimes there are good reasons not to follow the advice of a } \\
\text { physician. I have full knowledge of my health problem. }\end{array}$ \\
\hline 3 & COPE inventory ${ }^{79}$ & $\begin{array}{l}\text { I focus on dealing with this problem, and if necessary let other } \\
\text { things slide a little. }\end{array}$ \\
\hline 3 & $\begin{array}{l}\text { Medical Outcomes Study-Social Support } \\
\text { Survey }\end{array}$ & $\begin{array}{l}\text { Is there someone you can count on to listen to you when you need } \\
\text { to talk? }\end{array}$ \\
\hline
\end{tabular}

Person-environment-oriented attributes

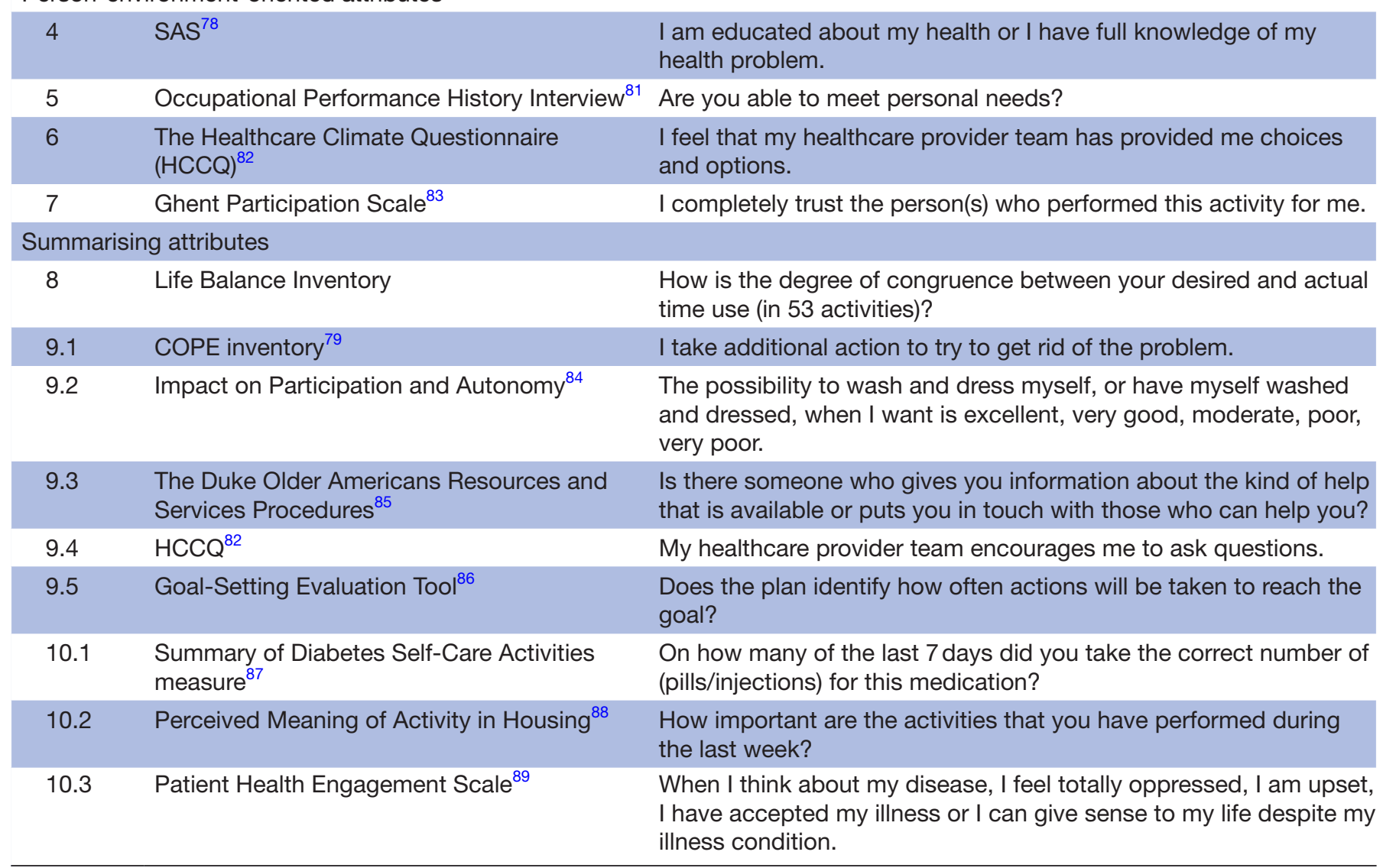

emotional and role management. ${ }^{32} 34$ These 10 attributes can be used as a lever to exceed this narrow level of medical management. Specifically, because there is a need for a focus on self-management based on a more activity-oriented vision and consequently consideration of emotional and role management. ${ }^{32}$ This means also that more attention should be given to aspects of goal-setting in performing activities of daily living (eg, I want to be able to pick up my grandchild from school) rather than solely focusing on goals related to the medical condition (eg, I want to take in my medication on time). This is in line with Richardson et $a l^{44}$ who argue that self-management should be seen as empowering patients to be active and motivated in managing their chronic condition in their real-life context and is in line with theoretical concepts such as goal-oriented care ${ }^{70}$ in which it is argued for the need to evolve from purely medical to broader behavioural management. This shows the slowly increasing interest in the other two domains besides medical management. Focusing on these three domains would provide an improved fit with a biopsychosocial model, rather than solely with the biomedical paradigm. ${ }^{4}$

However, this means that optimal self-management behaviour, aiming to incorporate each of the 10 attributes, is difficult and demands substantial effort, not only from the professionals, but primarily from the patient. ${ }^{72}$ In this regard, to empower patients to perform optimal self-management behaviour, a wide variety of coaching tools should be developed. E-health technologies are expected to play an important role in supporting patients in their self-management behaviour, ${ }^{72}$ but needs further development and should be tailored to the individual. From the 


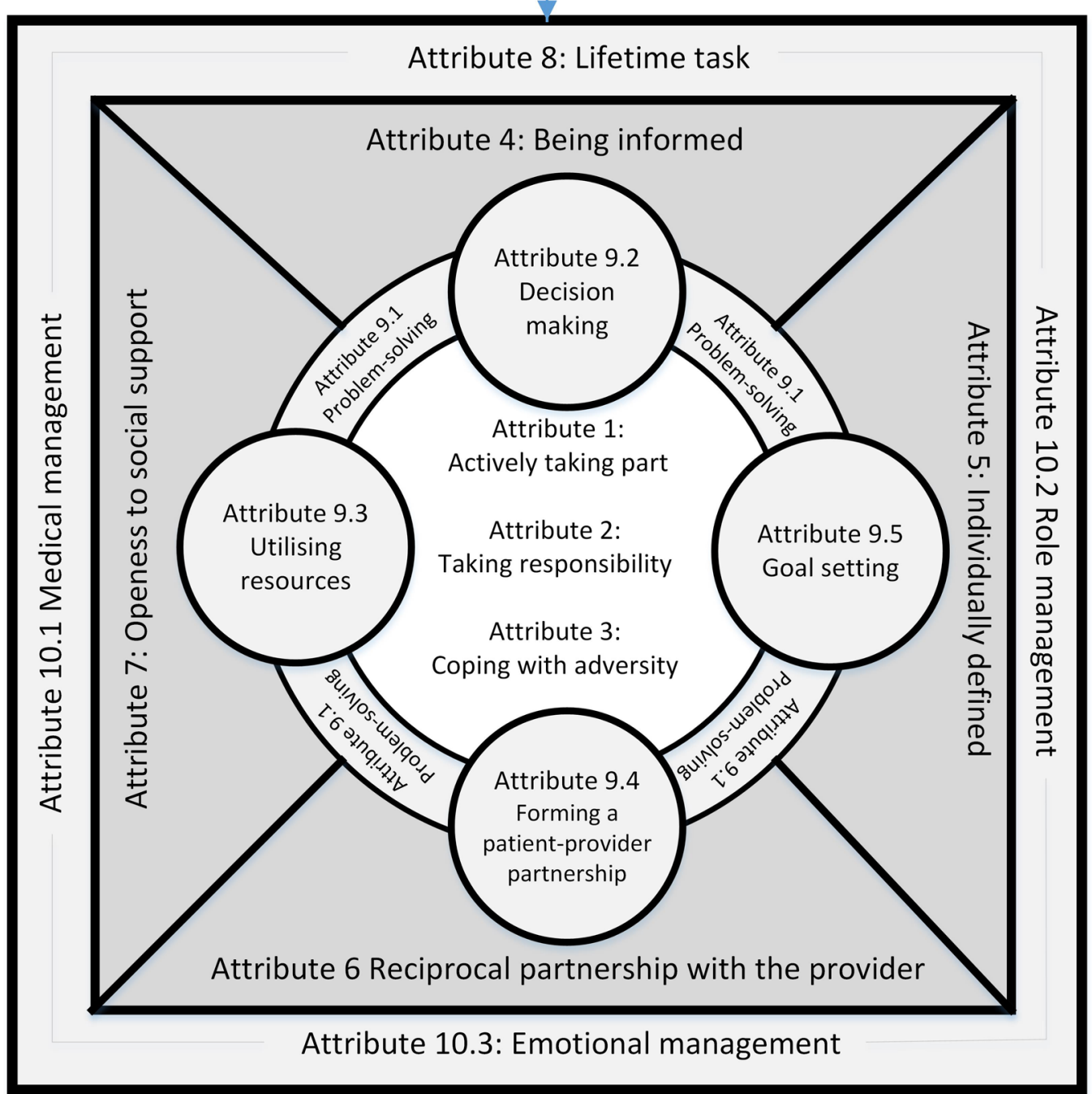

Figure 2 A schematic representation of the self-management attributes.

clients' perspective, it is crucial that healthcare professionals recognise the current level and readiness for self-management of the individual client. Patients want their strengths to be identified and empowered. ${ }^{73}$

However, the effectiveness of self-management intervention and its relation with health status has already been shown. The outcomes of randomised controlled studies have pointed out that self-management programmes generally improve health status, ${ }^{15} 181946$ and health behaviours, although limited. ${ }^{23}{ }^{24}$ Lorig and Holman ${ }^{34}$ found that the associations between improvements in patients' behaviours and improvements in health status were weak to non-existent. Also, in other studies, there are no convincing arguments about this relationship. ${ }^{74}$ This aspect is of particular interest when considering self-management as part of the definition of health because it questions whether there is already enough evidence to change the health paradigm towards a more dynamic definition of health and incorporating self-management in the definition.

Improving our in-depth knowledge about self-management and creating common ground on how interventions should be developed opens up possibilities to compare programmes, improve the quality of existing programmes. It can also add to the emerging evidence that improved self-management behaviour can reduce hospitalisation and total healthcare utilisation. ${ }^{8}$ This result, however, should be considered with care. For instance, there is empirical evidence that the length of stay (number of days) in hospital is positively correlated with improved self-management. ${ }^{43}$ This might inspire researchers to assume that a reduced number of days in hospital results in a decrease in self-management and plead in favour of longer hospital admissions. More research is needed to study the link between self-management and 'reduced healthcare utilisation' and what types of healthcare utilisation are necessary and which are not. This argument relates to the attribute 'the patient must be informed about the condition, disease and treatment' because it suggests well-considered and adequate hospitalisations and healthcare utilisation in general. Further investigation will be needed to show whether revision of this attribute or a review of the consequence 'reduced healthcare utilisation' is necessary. The way in which Miller $e t a \bar{l}^{1}$ described the consequence 'healthcare resource utilisation' 
could be a broader proposition because it is out of the question to look for declining numbers in healthcare utilisation. If future research shows that self-managing individuals are related to a higher number of hospitalisations, then that is a fact. We cannot assume that self-management is linked to fewer hospitalisations without strong evidence.

\section{LIMITATIONS AND RECOMMENDATIONS}

A concept analysis is a dynamic methodology and is sensitive to cultural, contextual and societal changes, although it is a very structured and systematic mode of analysis. This time-dependent methodology can produce different results over a few years, depending on the new knowledge that emerges from new insights. Nevertheless, this kind of inquiry has its own advantages. Following the various steps encourages communication and fosters theory development and research. This will enhance understanding among colleagues and may enable researchers to construct measurement instruments for the concept concerned. ${ }^{27}$ However, other methods of concept analysis (eg, Wilson's method, the hybrid model of concept analysis and Rodgers' evolutionary method) were also available, but found to be less accessible. ${ }^{75}$ One disadvantage in all concept analyses is the non-random sampling method. This means that the articles included might have been systematically different from those excluded, indicating a selection bias. This could lead to an unrepresentative image of self-management articles ${ }^{76}$ overall, as could have been the case in, for instance, a systematic review. However, this method allowed us to stop searching when saturation occurred and no new information was gathered; such a method facilitates a more targeted way of searching for evidence.

One important pitfall in this method is the difficulty to allocate characteristics as an attribute or as an antecedent of consequence. In this specific study, it is about the allocation of 'self-efficacy' and 'social support'.

Depending on the different authors, self-efficacy can be regarded as an attribute, antecedent or consequence. However, based on the method employed,${ }^{27}$ an antecedent or consequence cannot be an attribute at the same time. We did not find conclusive arguments for any particular assignment, although the majority of authors view self-efficacy as an antecedent, ${ }^{32-34} 373941$ and because self-efficacy is viewed as a meaningful mechanism for facilitating self-management, ${ }^{34}$ we primarily chose to allocate it as an antecedent. Also, 'social support' can be seen as an attribute or an antecedent. When it is assumed that social support is an attribute, it encourages the assumption that individuals with or without a weak social network can never achieve self-management. The main reason for allocating it as an attribute is the changing view on self-management, from one in which self-management is seen as a primarily individualistic behavioural change ${ }^{37}$ towards one in which it is considered a behavioural change that is, to a great extent, facilitated through social support, including both professional and non-professional. ${ }^{28} 414650515759$ This aspect underpinned our choice to allocate social support as an attribute because it seems to be an inevitable feature. Regarding this evolution, there have been attempts to progress from self-management towards co-management.

The most decisive elements of self-management became apparent through the defined attributes, but mutual relationships must be elucidated. The attributes have now been described based in a logical order. However, the question is whether there is somehow a conditionality within the different attributes; for example, can someone who is more informed (attribute 4) take greater responsibility (attribute 2) in his care process. This aspect has not been researched in the current study, but offers opportunities for further research.

In the context of the measurability of self-management, the empirical referents are quite clear, but could also be studied in greater depth, because the examples given in this study can only be considered exemplary. The development of a valid and reliable instrument to measure self-management encompassing all attributes would enable researchers to compare the results of effectiveness studies. As yet, it is very difficult to compare research results because no gold standard for self-management is available.

\section{CONCLUSION}

The results of this concept analysis offer possibilities for practice, research and education. As previously mentioned, the development of a conceptual framework enhances understanding between practitioners and researchers. This concept analysis also has added value at the educational level. ${ }^{77}$ Because of the rising medical costs, alternatives for keeping healthcare organised are being sought. These notable changes are greatly influencing the education of healthcare providers. Therefore, patients need to be educated and healthcare providers need to be trained in facilitating self-management skills. This means that self-management competencies must be part of healthcare curricula.

The results of this concept analysis have favourable implications for practice, research and education. However, more research is needed to develop a measure including all of the attributes.

\section{PATIENT AND PUBLIC INVOLVEMENT STATEMENT}

There were no patients involved in this study. The names of the persons mentioned in the model case and in the additional cases are fictitious.

\section{Author affiliations \\ ${ }^{1}$ Faculty of Medicine and Health Sciences, Department of Rehabilitation Sciences, Occupational Therapy Program, Ghent University, Ghent, Belgium \\ ${ }^{2}$ Occupational Therapy, Artevelde University College, Ghent, Belgium \\ ${ }^{3}$ Occupational Therapy, HAN University of Applied Sciences, Nijmegen, The Netherlands \\ ${ }^{4}$ Occupational Therapy and Occupational Science, Health University of Applied Science Tyrol, Innsbruck, Austria \\ ${ }^{5}$ Occupational Therapy, School of Health Professions, Zurich University of Applied Sciences, Winterthur, Switzerland}


${ }^{6}$ Department of Gerontology and Frailty in Ageing Research Group, Vrije Universiteit, Brussel, Belgium

Contributors DVdV and FDZ led the writing of the manuscript. DVdV, FDZ and SJ analysed and interpreted the data. FDZ and SJ had substantial contribution in data acquisition, analysis and interpretation. DVdV and PDV had substantial contribution in the study conception and design, data analysis and interpretation. UC, DS and TS served as external experts to increase the credibility of the findings. All authors revised and approved the final version of the manuscript.

Funding The authors have not declared a specific grant for this research from any funding agency in the public, commercial or not-for-profit sectors.

Competing interests None declared.

Patient consent for publication Not required.

Provenance and peer review Not commissioned; externally peer reviewed.

Data sharing statement There are no additional data in this study.

Open access This is an open access article distributed in accordance with the Creative Commons Attribution Non Commercial (CC BY-NC 4.0) license, which permits others to distribute, remix, adapt, build upon this work non-commercially, and license their derivative works on different terms, provided the original work is properly cited, appropriate credit is given, any changes made indicated, and the use is non-commercial. See: http://creativecommons.org/licenses/by-nc/4.0/.

\section{REFERENCES}

1. WHO. Constitution of the World Health Organisation 2006. 2016. Available www.xho.int/governance/eb/who_constitutio_en.pdf (Accessed 28 Nov 2017).

2. Lancet T. What is health? The ability to adapt. Lancet 2009;373:781-6736.

3. Huber M, Knottnerus JA, Green L, et al. How should we define health? BMJ 2011;343:d4163

4. Van de Velde D, Eijkelkamp A, Peersman W, et al. How competent are healthcare professionals in working according to a bio-psychosocial model in healthcare? The current status and validation of a scale. PLoS One 2016;11:e0164018.

5. De Maeseneer J, Boeckxstaens P. James Mackenzie Lecture 2011: multimorbidity, goal-oriented care, and equity. $\mathrm{Br} J$ Gen Pract 2012;62:e522-4

6. Fortin M, Hudon C, Haggerty J, et al. Prevalence estimates of multimorbidity: a comparative study of two sources. BMC Health Serv Res 2010;10:111.

7. WHO. Global action plan for the prevention and control of noncommunicable diseases 2013-2020. Geneve: World Health Organisation, 2013.

8. Panagioti M, Richardson G, Small N, et al. Self-management support interventions to reduce health care utilisation without compromising outcomes: a systematic review and meta-analysis. BMC Health Serv Res 2014;14:356.

9. Wahowiak L. Providing lifelong education and support: updates in the 2017 National Standards for Diabetes Self-Management Education and Support. Diabetes Spectr 2017;30:298-300.

10. Barlow JH, Barefoot J. Group education for people with arthritis. Patient Educ Couns 1996;27:257-67.

11. McKenna S, Jones F, Glenfield P, et al. Bridges self-management program for people with stroke in the community: A feasibility randomized controlled trial. Int J Stroke 2015;10:697-704.

12. Andersen LN, Juul-Kristensen B, Roessler KK, et al. Efficacy of 'Tailored Physical Activity' on reducing sickness absence among health care workers: A 3-months randomised controlled trial. Man Ther 2015;20:666-71.

13. Brody BL, Williams RA, Thomas RG, et al. Age-related macular degeneration: a randomized clinical trial of a self-management intervention. Ann Behav Med 1999;21:322-9.

14. Kos D, Duportail M, Meirte J, et al. The effectiveness of a selfmanagement occupational therapy intervention on activity performance in individuals with multiple sclerosis-related fatigue. Int J Rehab Res 2016;39:255-62.

15. Detaille SI, Heerkens YF, Engels JA, et al. Effect evaluation of a self-management program for dutch workers with a chronic somatic disease: a randomized controlled trial. J Occup Rehabil 2013;23:189-99.

16. Pinxsterhuis I, Sandvik L, Strand EB, et al. Effectiveness of a group-based self-management program for people with chronic fatigue syndrome: a randomized controlled trial. Clin Rehabil 2017;31:93-103.

17. Kendall E, Catalano T, Kuipers $P$, et al. Recovery following stroke: the role of self-management education. Soc Sci Med 2007;64:735-46.

18. Davis AH, Carrieri-Kohlman V, Janson SL, et al. Effects of treatment on two types of self-efficacy in people with chronic obstructive pulmonary disease. J Pain Symptom Manag 2006;32:60-70.

19. Dziedzic K, Nicholls E, Hill S, et al. Self-management approaches for osteoarthritis in the hand: a $2 \times 2$ factorial randomised trial. Ann Rheum Dis 2015;74:108-18.

20. Ghahari S, Leigh Packer T, Passmore AE. Effectiveness of an online fatigue self-management programme for people with chronic neurological conditions: a randomized controlled trial. Clin Rehabil 2010;24:727-44.

21. Spadaro A, De Luca T, Massimiani MP, et al. Occupational therapy in ankylosing spondylitis: Short-term prospective study in patients treated with anti-TNF-alpha drugs. Joint Bone Spine 2008;75:29-33.

22. Monninkhof $\mathrm{E}$, van der Valk $\mathrm{P}$, van der Palen $\mathrm{J}$, et al. Effects of a comprehensive self-management programme in patients with chronic obstructive pulmonary disease. Eur Respir J 2003;22:815-20.

23. Cameron-Tucker H, Wood-Baker R, Owen C, et al. Chronic disease self-management and exercise in COPD as pulmonary rehabilitation: a randomized controlled trial. Int $J$ Chron Obstruct Pulmon Dis 2014;9:513-23

24. Siu AM, Chan CC, Poon PK, et al. Evaluation of the chronic disease self-management program in a Chinese population. Patient Educ Couns 2007;65:42-50.

25. Jonkman NH, Schuurmans MJ, Groenwold RHH, et al. Identifying components of self-management interventions that improve health-related quality of life in chronically ill patients: Systematic review and meta-regression analysis. Patient Educ Couns 2016;99:1087-98.

26. Pearce G, Parke HL, Pinnock H, et al. The PRISMS taxonomy of self-management support: derivation of a novel taxonomy and initial testing of its utility. J Health Serv Res Policy 2016;21:73-82.

27. Walker L, Avant K. Strategies for theory construction in nursing. 5th edn. Edinburgh: Pearson, 2014.

28. Omisakin F, Ncama B. Self, self-care and self-management concepts: implications for self-management education. Educ Res $2011 ; 2: 5$

29. Bodenheimer T, Lorig $\mathrm{K}$, Holman $\mathrm{H}$, et al. Patient self-management of chronic disease in primary care. JAMA 2002;288:2469.

30. Audulv $\AA$. The over time development of chronic illness selfmanagement patterns: a longitudinal qualitative study. BMC Public Health 2013;13:452.

31. Clement S. Diabetes self-management education. Diab Care 1995;18:1204-14.

32. Packer TL. Self-management interventions: using an occupational lens to rethink and refocus. Aust Occup Ther J 2013;60:1-2.

33. Bodenheimer T, MacGregor K, Shariff C. Helping patients manage their chronic conditions: California HealthCare Foundation, 2005.

34. Lorig KR, Holman H. Self-management education: history, definition, outcomes, and mechanisms. Ann Behav Med 2003;26:1-7.

35. Boger E, Ellis J, Latter S, et al. Self-management and selfmanagement support outcomes: a systematic review and mixed research synthesis of stakeholder views. PLoS One 2015;10:e0130990.

36. Taylor D, Bury M. Chronic illness, expert patients and care transition. Sociol Health IIIn 2007;29:27-45.

37. Ellis J, Boger E, Latter S, et al. Conceptualisation of the 'good' self-manager: A qualitative investigation of stakeholder views on the self-management of long-term health conditions. Soc Sci Med 2017;176:25-33.

38. Kitt J, Beaton B, Cook C, et al. Self-management support for Canadians with chronic health conditions. Toronto: Health Council of Canada, 2012.

39. Edworthy SM. How important is patient self-management? Baillieres Best Pract Res Clin Rheumatol 2000;14:705-14.

40. Packer T. An occupation-focused approach to self-management. Occup Ther Now 2011;13:1.

41. Barlow J, Wright C, Sheasby J, et al. Self-management approaches for people with chronic conditions: a review. Patient Educ Couns 2002;48:177-87.

42. Clark N, Becker M, Janz N, et al. Self-management of chronic disease by older adults: a review and questions for research. J Aging Health 1991;3:24.

43. Lorig KR, Sobel DS, Ritter PL, et al. Effect of a self-management program on patients with chronic disease. Eff Clin Pract 2001;4:256-62.

44. Lorig KR, Sobel DS, Stewart AL, et al. Evidence suggesting that a chronic disease self-management program can improve health 
status while reducing hospitalization: a randomized trial. Med Care 1999;37:5-14.

45. Schulman-Green D, Jaser S, Martin F, et al. Processes of selfmanagement in chronic illness. J Nurs Scholarsh 2012;44:136-44.

46. Barlow JH, Turner AP, Wright CC. A randomized controlled study of the Arthritis Self-Management Programme in the UK. Health Educ Res 2000;15:665-80.

47. Lawn S, McMillan J, Pulvirenti M. Chronic condition selfmanagement: expectations of responsibility. Patient Educ Couns 2011;84:e5-e8.

48. Norris SL, Engelgau MM, Narayan KM. Effectiveness of selfmanagement training in type 2 diabetes: a systematic review of randomized controlled trials. Diabetes Care 2001;24:561-87.

49. Richardson J, Loyola-Sanchez A, Sinclair S, et al. Self-management interventions for chronic disease: a systematic scoping review. Clin Rehabil 2014;28:1067-77.

50. Audulv À, Packer T, Hutchinson S, et al. Coping, adapting or selfmanaging - what is the difference? A concept review based on the neurological literature. J Adv Nurs 2016;72:2629-43.

51. Miller WR, Lasiter S, Bartlett Ellis R, et al. Chronic disease self-management: a hybrid concept analysis. Nurs Outlook 2015;63:154-61.

52. Thille P, Ward N, Russell G. Self-management support in primary care: enactments, disruptions, and conversational consequences. Soc Sci Med 2014;108:97-105.

53. Wilkinson A, Whitehead L. Evolution of the concept of self-care and implications for nurses: a literature review. Int J Nurs Stud 2009;46:1143-7.

54. van de Wiel HB, Weijmar Schultz WC. Self management: a new paradigm in patient education? J Psychosom Obstet Gynaecol 2004;25:85-6.

55. van Schie D, Castelein S, van der Bijl J, et al. Systematic review of self-management in patients with schizophrenia: psychometric assessment of tools, levels of self-management and associated factors. J Adv Nurs 2016;72:2598-611.

56. Richard AA, Shea K. Delineation of self-care and associated concepts. J Nurs Scholarsh 2011;43:no-64.

57. Alderson M, Starr L, Gow S, et al. The program for rheumatic independent self-management: a pilot evaluation. Clin Rheumatol 1999;18:283-92.

58. Bayliss EA, Ellis JL, Steiner JF. Barriers to self-management and quality-of-life outcomes in seniors with multimorbidities. Ann Fam Med 2007;5:395-402.

59. Raymond K, Levasseur M, Chouinard M-C, et al. Stanford Chronic Disease Self-Management Program in myotonic dystrophy: New opportunities for occupational therapists. Can J Occup Ther 2016;83:166-76.

60. Clark N, Janz N, Dodge J, et al. Self-management of heart disease by older adults: Assessment of an intervention based on social cognitive theory. Res Aging 1997:19:20.

61. Ghahari S, Packer T. Effectiveness of online and face-to-face fatigue self-management programmes for adults with neurological conditions. Disabil Rehabil 2012;34:564-73.

62. Corbin J, Strauss AL. Unending work and care: managing chronic illness at home: Jossay-Bass, 1988

63. Dunbar SB, Jacobson LH, Deaton C. Heart failure: strategies to enhance patient self-management. AACN Clin Issues 1998;9:244-56.

64. Wilde MH, Garvin S. A concept analysis of self-monitoring. J Adv Nurs 2007;57:339-50.

65. Dodd M, Janson S, Facione N, et al. Advancing the science of symptom management. J Adv Nurs 2001;33:668-76.

66. Girdler SJ, Boldy DP, Dhaliwal SS, et al. Vision self-management for older adults: a randomised controlled trial. Br J Ophthalmol 2010;94:223-8

67. Newbould J, Taylor D, Bury M. Lay-led self-management in chronic illness: a review of the evidence. Chronic IIIn 2006;2:249-61.
68. Mackey L, Doody C, Werner E, et al. Self-management skills in chronic disease management: what role does health literacy have? Med Decis Making 2016;36:18.

69. Warsi A, Wang PS, LaValley MP, et al. Self-management education programs in chronic disease: a systematic review and methodological critique of the literature. Arch Intern Med 2004:164:1641-9.

70. Mold JW, Blake GH, Becker LA. Goal-oriented medical care. Fam Med 1991;23:46-51.

71. Reuben DB, Tinetti ME. Goal-oriented patient care--an alternative health outcomes paradigm. N Engl J Med 2012;366:777-9.

72. Huygens MW, Vermeulen J, Swinkels IC, et al. Expectations and needs of patients with a chronic disease toward self-management and eHealth for self-management purposes. BMC Health Serv Res 2016;16:232.

73. Lawn S, Battersby M, Lindner $\mathrm{H}$, et al. What skills do primary health care professionals need to provide effective self-management support?Seeking consumer perspectives. Aust J Prim Health 2009;15:37

74. Lenker SL, Lorig K, Gallagher D. Reasons for the lack of association between changes in health behavior and improved health status: an exploratory study. Patient Educ Couns 1984;6:69-72.

75. Cronin P, Ryan F, Coughlan M. Concept analysis in healthcare research. Int J Ther Rehabil 2010;17:62-8.

76. Sedgwick P. Snowball sampling. BMJ 2013;347:f7511.

77. Pols RG, Battersby MW, Regan-Smith M, et al. Chronic condition self-management support: proposed competencies for medical students. Chronic IIIn 2009;5:7-14.

78. Brashers DE, Haas SM, Neidig JL. The patient self-advocacy scale: measuring patient involvement in health care decision-making interactions. Health Commun 1999;11:97-121.

79. Carver CS, Scheier MF, Weintraub JK. Assessing coping strategies: a theoretically based approach. J Pers Soc Psychol 1989;56:267-83.

80. Sherbourne CD, Stewart AL. The MOS social support survey. Soc Sci Med 1991;32:705-14.

81. Kielhofner G. Model of human occupation, theory and application. 4 edn. Philadelphia: Lippincott Williams and Wilkins, 2008.

82. Ludman EJ, Simon GE, Rutter CM, et al. A measure for assessing patient perception of provider support for self-management of bipolar disorder. Bipolar Disord 2002;4:249-53.

83. Van de Velde D, Coorevits P, Sabbe L, et al. Measuring participation as defined by the World Health Organization in the International Classification of Functioning, Disability and Health. Psychometric properties of the Ghent Participation Scale. Clin Rehabil 2017;31:379-93.

84. Cardol M, de Haan RJ, van den Bos GAM, et al. The development of a handicap assessment questionnaire: the Impact on Participation and Autonomy (IPA). Clin Rehabil 1999;13:411-9.

85. Fillenbaum GG. Multidimensional functional assessment of older adults: the Duke Older Americans Resources and Services Procedures. Erlbaum, Hillsdale, N.J, 1988.

86. Teal CR, Haidet $P$, Balasubramanyam AS, et al. Measuring the quality of patients' goals and action plans: development and validation of a novel tool. BMC Med Inform Decis Mak 2012;12:152.

87. Mayberry LS, Gonzalez JS, Wallston KA, et al. The ARMS-D out performs the SDSCA, but both are reliable, valid, and predict glycemic control. Diabetes Res Clin Pract 2013;102:96-104.

88. Eklund $M$, Brunt $D$. Measuring opportunities for engaging in meaningful home-based activities in housing services for people with psychiatric disabilities: Development of the perceived meaning of activity in housing (PMA-H). Eval Health Prof 2017;163278717727333.

89. Graffigna G, Barello S, Bonanomi A, et al. Measuring patient engagement: development and psychometric properties of the Patient Health Engagement (PHE) Scale. Front Psychol 2015;6:274. 